\title{
FROM ANALYTICAL LENSES AND SOCIAL POLICIES: A LOOK FROM THE EMOTIONS
}

\author{
SOCIAL POLICIES AND EMOTIONS. A LOOK FROM THE GLOBAL \\ SOUTH, BY ANGÉLICA DE SENA AND ADRIAN SCRIBANO \\ (PALGRAVE MACMILLAN, 2020)
}

\author{
ANDREA DETTANO
}

This book was written by Angélica De Sena and Adrian Scribano, researchers at the National Council for Scientific and Technical Research (CONICET) in Argentina. They have published several pieces of work related to social policies, research methodologies, and the sociology of bodies and emotions. Angélica De Sena has published different books and articles that develop understanding of the crucial place of emotions in the analysis of state interventions. She also is the head of the Study Group about Social Policies and Emotions. Adrian Scribano's work is a landmark in the study of bodies and emotions in Argentina. He has published several books about collective action, consumption and love, among other topics. He also heads the International Network of Sociology of Sensibilities.

Social policies, the central object of the book under review, have been defined from multiple standpoints and disciplinary fields. These efforts seem to converge in giving these interventions a tensional and contradictory character, since they express the tension between the freedom and formal equality of subjects and the living conditions imposed by the commercialization of the workforce, which permanently recreate dependency and subordination in various forms. In view of this tensional nature and the constant allusion to inequalities, vulnerabilities, and the lack of protection that seem to historically "border" this object, the book here reviewed offers an analysis that is auspicious in several ways. The analytical advancement of this work consists in how it enables articulation

1 Andrea Dettano Posdoctoral fellow at the National Council for Scientific and Technical Research (CONICET) and professor at the University of Buenos Aires and at the National University of La Matanza (UNLaM Argentina, email: andreadettano@gmail.com 
between social policies and emotions and observes how state interventions are constructed, experienced, and felt.

If we think about these policies from the perspective of their historical constitution, the consolidation of the different types of interventions have required the - slow and gradual - establishment of institutional commitments to provide their subjects with some "certainties" with respect to the management of their reproductive conditions. These conditions have assumed, and continue to assume, a changing character which is specified and established each time as the product of political and social disputes. In all their dimensions and aspects, and in each context, they have been articulated by different actors and institutions.

In general, as "ways of doing" of the State, social policies have collaborated with the reproduction of the agents under their coverage, and with the reproduction of the regime in the long term. Through the regulation and transfer of goods or services with different levels of impact on the lives of the subjects who perceive them, the former organize the distribution of burdens, benefits, and power between groups and categories of people.

Considering the aforementioned, this book recovers how the "places" of provision (the State, the market, the family, the organizations of civil society); the goods in question (money, food, housing, different kind of goods, services associated with salaries); the justifications (the achievement of inclusion, autonomy, empowerment, and sustainability); and the emotions and sociabilities at stake (fear, mistrust, responsibility and uncertainty) are the features that characterize state interventions and are modified in each case and particular time-space.

In view of their complexity, and because they are traversed by various elements, proposals and debates in each era, as well as by the forms of accumulation, distribution, and consumption, these interventions show centrality, mainly in scenarios such as the current one that is marked by the health emergency in the context of a global pandemic. This scenario reaffirms the centrality of rethinking the State's ways of intervening, the practices it enables and restricts, as well as the different ways of feeling which these interventions produce. This (in view of the fact that the State and its role is never innocuous), is always a space for the production of meanings and senses that establish the correct ways of being and being with others in the world; it establishes classifications and qualifications of subjects and their practices.

Social policies, as well as the ways of observing and defining them, require re-problematization and revision in the light of the structuring processes of this century. If their emergence has been related to the processes of industrialization and urbanization within the framework of the much-cited Social Question during the nineteenth century; if they were concretized and institutionalized 
in the different forms of the Welfare State and then reorganized before the transformations of the world of labour that unfolded towards the end of the twentieth century, then the twenty-first century claims its own analytical lenses. In this sense, this book presents different images with which to reflect on current scenarios; it looks - from the standpoint of emotions and from the Global South - at increasingly massive and prevailing state practices.

In its eleven chapters, it addresses the relationship of social policies with education and consumption; the different ways in which the different programs "put the beneficiaries to work" at different forms of "employability;" the ways in which violence appears as a constitutive element of contexts marked by poverty; the normalization of immediate enjoyment through consumption; and the ways in which state interventions are increasingly shaped as incentives for promoting such consumption. The ways in which state interventions and programs shape and consolidate what the authors understand as the "politics of sensibilities" are also addressed. In addition, they give an account of the different forms that ways of intervening and serving the population in situations of poverty and/ or vulnerability are assuming: from the much-cited Conditional Cash Transfer Programs to food policies.

A look from the Global South implies considering, as this work develops, the proliferation and massiveness of the different interventions of the State aimed at ameliorating that which once assumed a residual character: unemployment and poverty. The object, population, scope and coverage of the former, as well as the different ways of "assisting," have been transformed. This enables the book to ask the question - as well as provide some answers about - how the feelings and sensibilities of millions of subjects who receive state assistance are shaped; what bodies are consolidated; and what images of the world operate in the designs of the interventions, thereby establishing the correct ways of being, doing, caring, looking for a job, and being beneficiaries, among other elements.

In addition to the different themes that are explored, the book constitutes a journey that exhibits extensive supporting empirical work from primary and secondary data sources that provides an observational lens that invites us to denature certain common sites of state assistance; their association with benevolent, altruistic and tied actions; and the achievements of social rights. It allows us not only to consider something present in multiple documents, articles, books, and/or impact evaluations (such as the problem of poverty, its possible causes, diagnoses and ways of "overcoming"); but it also enables us to begin considering - due to the analysis of several in-depth interviews with recipients - how large-scale state interventions are experienced and perceived by recipients as a way of comparing autonomies and possible dependencies. Both the study and the fieldwork were focused on the Greater Buenos Aires area - the 
most populated location in Argentina. Nevertheless, the different programs and situations that are studied show constant dialogue between various countries of the Latin American region and other countries which make up the so-called Global South. The development presented in the book allows us to reflect on the possibility of establishing certain general features of social policies in current scenarios such as massiveness, access by the population to banking services, and monetization amid major transformation in the job market.

Starting from maintaining that state interventions materialized in social policies affect how actors behave in various ways, the different chapters organize ways of displaying these possible forms of involvement. Interventions that for decades have materialized as different ways of distributing food, but not the guarantee of nutrients, present an elementary edge for thinking about social policies in terms of the effects and corporeality that they constitute. This has meant that different generations have organized their eating practices around "what is received," or what can be obtained with income from programs, or from attending community kitchens. This not only organizes dinners, but also organizes a map of possible energies, as the former allow some access to foods that produce satiety, but whose nutritional composition appears insufficient.

In this sense, the programs and different forms of food transfer not only affect the production and material reproduction processes, directly impacting the possibilities of action through the distribution of socially available nutrients, but also the production and reproduction of the perception of the schemes that enables some social practices, but not others.

Therefore, each chapter raises issues that enable a more complex view of state interventions, adding elements such as consumption, the formation of "weak bodies" and thinking about the effects that they entail in the reproduction of populations. If social policies, in their definitions and contributions, are objects that seek to influence living conditions, the questions that this text address is what are those conditions, how are they experienced, what feelings do they produce, and what bodily and social energies do they enable? It also raises questions about the "transience" of ways of tackling poverty, whose scope and coverage is increasing.

Looking from the emotions implies, for this volume, considering the latter as bodily, cognitive and social elements, which in the experience of being in the world and with others are armed, consolidated and plotted, configuring the different ways of appreciating and perceiving everyday life. Emotions then appear as constitutive ingredients of social action, interaction, and ways of being. Furthermore, different types of devices and mechanisms developed by the authors are what allow us to understand how naturalizations are possible that allow us to experience, in an unnoticed way, the inequalities and expropriations 
that capitalism establishes. They even add the operation of different forms of the trivialization of the good as ways of desensitizing the sensitivity to inequality, poverty, malnutrition, difficulties in accessing social services and permanence in the educational system, among other aspects.

That is, how the different state actions - which have been presented as various ways of achieving objectives related to issues such as social inclusion, well-being, and increasing so-called human capital - have become a plexus of compensatory actions that allow consumption - but not much; they allow people to eat - but not to be nourished; they allow subjects to comply with the different conditions and considerations that the programs require - but not to be employed. In this sense, politics of sensibilities are being consolidated as the authors maintain: that is, ways of feeling are being accepted and acceptable in a specific time-space that organize daily life, preferences and values and the parameters for managing that time-space.

Along these lines, this book incorporates the emotional aspect of the subjects' relationship with the State, considering ways of feeling as antecedents of the interventions which constitute and consolidate their designs and approaches, as well as their effects, when considering what they produce in the subjects and in the modes of social structuring. Having said this, in contexts such as the current ones, reading this book is a central contribution to reconsidering the dimension and scope that the policies of attention to poverty show in terms of its intergenerational nature and its relationship with different phenomena. All that has been said shows that they represent a complex and multidimensional analytical element whose approach requires intersections and articulations such as those proposed by the authors: a look from the emotions. 
